\title{
VIOLACIÓN DE LA NEUTRALIDAD DE ESPAÑA DURANTE LA SEGUNDA GUERRA MUNDIAL
}

\author{
Matilde MORCILLO \\ Universidad de Castilla-La Mancha
}

Recibido: 03/09/2012

Aceptado: 04/11/2013

RESUMEN: El objeto de este trabajo es poner de manifiesto, a través de la correspondencia diplomática, cómo se violó la neutralidad de España durante la Segunda Guerra Mundial, señalando algunos de los casos más significativos con un enfoque distinto hasta el presente.

Especial atención requiere la denuncia de España a Francia por violar el espacio aéreo español durante la guerra, mientras Inglaterra protestaba por las facilidades, contrarias a la neutralidad, dadas por Franco a los aviones y buques de las potencias del Eje en territorio español, al propio tiempo que Inglaterra y Alemania también violaban la neutralidad de España.

PALABRAS CLAVE: violación, neutralidad, España, Segunda Guerra Mundial, Francia, Alemania, Inglaterra.

ABSTRACT: The purpose of this article is to show, through the diplomatic correspondence, how Spain's neutrality was violated during the $2^{\text {nd }}$ World War. It will be pointed out some of the most significant cases with a different approach up to the present.

Special attention requires the accusation of Spain to France for violating Spanish air space during the war, while England complained about the facilities, contrary to neutrality, granted by Franco to airplanes and ships of the Axis powers in Spanish territory, at the same time while England and Germany were also violating the neutrality of Spain.

KEYWORDS: violation, neutrality, Spain, $2^{\text {nd }}$ World War, France, Germany, England .

\section{ACTITUD DE ESPAÑA DURANTE LA SEGUNDA GUERRA MUNDIAL}

Como se sabe, la actitud de España durante la Segunda Guerra Mundial fue desde la declaración de neutralidad a la no beligerancia para terminar de nuevo con la neutralidad.

El 1 de septiembre de 1939 comenzaba la Segunda Guerra Mundial, y el 4 del mismo mes Franco aprobaba un decreto ordenando a los españoles la más estricta neutralidad. Así lo recogía el diario «La Vanguardia Española»: «Emocionado 
llamamiento del Caudillo a los españoles. Se ordena a los españoles que observen la más estricta neutralidad». ${ }^{1}$.

Por su parte, el diario «Solidaridad Nacional» ${ }^{2}$ señalaba que España mantendría la neutralidad por decisión del Caudillo. Esta decisión influiría en el ánimo de muchos países a mantenerse también neutrales ${ }^{3}$. Además, en junio de 1940, fuerzas españolas penetraban en Tánger, y España garantizaba la neutralidad de la zona ${ }^{4}$.

La estricta neutralidad se mantuvo durante diez meses aproximadamente. El ministro de Asuntos Exteriores español, el coronel Juan Luis Beigbeder 5 , justificaba la decisión por la tradicional neutralidad de España, porque el conflicto no afectaba directamente a España y porque las condiciones del país, tras la guerra civil, exigían la reconstrucción nacional.

Después, Franco, al ver el transcurso de la guerra cambió de posición, pasando de la estricta neutralidad a la no beligerancia. Los éxitos militares de Alemania, la violación de la neutralidad de Holanda, Bélgica y Luxemburgo, la ocupación de Francia entre mayo y junio de 1940 y la entrada de Italia en la guerra en junio del mismo año hicieron que el general Franco cambiara de actitud y adoptara una postura favorable a las potencias del Eje ${ }^{6}$. El 12 de junio de 1940 el Consejo de Ministros español acordaba: "Extendida la lucha al Mediterráneo por la entrada de Italia, en guerra con Francia e Inglaterra, el gobierno ha acordado la no beligerancia de España en el conflicto».?

${ }^{1}$ La Vanguardia Española, 5 de septiembre de 1939, p. 1. Cfr. en Fernández Hita, A. (2006). «De la estricta neutralidad a la no beligerancia. La Vanguardia Española y Solidaridad Nacional durante la Segunda Guerra Mundial», p.13 [recurso electrónico]. http://www.solidaritat.ub. edu/premi_pau/2006/treballs/Estricta_neutralidad.pdf [Consultado: 5 de junio de 2012].

${ }^{2}$ Solidaridad Nacional, 5 de septiembre de 1939, p. 15. Cfr. en Fernández HitA, A. (2006). «De la estricta neutralidad a la no beligerancia. La Vanguardia y Solidaridad Nacional durante la Segunda Guerra Mundial»...,p. 15.

${ }^{3}$ La Vanguardia Española, 8 de septiembre de 1939..., p. 14.

${ }^{4}$ Solidaridad Nacional, 15 de junio de $1940 \ldots$, p. 19.

${ }^{5}$ Beigbeder: Juan Luis Beigbeder, ministro de Asuntos Exteriores español con Franco, entre el 12 de agosto de 1939 y el 16 de octubre de 1940.

${ }^{6}$ Stanton, S. (2009). «The Myth of Spain Neutrality: U.S. Foreign Relations with Spain, 19391941» [recurso electrónico]. http://artsci.drake.edu/dussj/stantonsean.pdf [consultado: 13-7-2012].

${ }^{7}$ Solidaridad Nacional, 14 de junio de 1940, p. 1 Cifr. en FernÁndeZ HitA, A. «De la estricta neutralidad a la no beligerancia. La Vanguardia y la Solidaridad Nacional durante la Segunda Guerra Mundial...», p. 21; Pereira, J.C. y P. MARTínez Lillo. (1998). «Política exterior, 1939-1975». En PAREDES, J. (Coord.). Historia Contemporánea de España (siglo XX). Barcelona: Ariel, pp. 729-730. 
Por ello, y según señalaba el Derecho Internacional, España, al decidir la no beligerancia, se abstenía provisionalmente de intervenir en la contienda y mantenía relaciones con los Estados beligerantes de Alemania e Italia como si éstos no estuvieran en guerra. Se trataría, pues, según algunos autores, de una neutralidad benévola. Esto explicará, como veremos más adelante, el trato favorable dado por España a las potencias del Eje en territorio nacional.

Posteriormente, la entrada de Estados Unidos en la guerra a finales de 1941 daría al conflicto un carácter mundial repercutiendo en España, que se apresuraba a confirmar la no beligerancia, pero la ruptura de relaciones de la mayor parte de los países de Iberoamérica con las potencias del Eje, se vio con gran preocupación en España.

Sería en el verano de 1942, al preparar los aliados el desembarco en el norte de África, y tras la declaración de Roosevelt a Franco, a través de una carta del embajador norteamericano, informando al caudillo de dicha operación y de que nada tenía que temer España ni su pueblo ni Marruecos ni otros territorios españoles, cuando Franco se sintiese más seguro de los aliados y con menos posibilidades de una hipotética intervención con el Eje, habida cuenta del fracaso de la entrevista de Franco y Hitler en Hendaya el 23 de octubre de 1940, y que el 11 de abril de 1943 Hitler desestimó definitivamente cualquier participación española en el conflicto, aunque las relaciones comerciales con Alemania siguieron siendo importantes, especialmente en lo referente a la exportación de volframio.

Ahora, Franco ya no sentía miedo y abogaba por una paz justa. Así, el 1 de octubre de 1943 el caudillo daba un giro a su postura y volvía a la más estricta neutralidad, advirtiendo que no cedería, bajo ningún concepto, ante presión alguna que alterase dicha neutralidad.

\section{Correspondencia del ministro de Asuntos Exteriores español al embajador de España en Berlín confirmando la neutralidad de España en la guerra.}

El ministro de Asuntos Exteriores, Francisco Gómez Jordana ${ }^{8}$, enviaba una carta al embajador español en Berlín, Ginés Vidal, dándole cuenta de la situación internacional en aquel momento y de la posición de España ante el conflicto.

En dicha carta, el ministro español ponía de relieve que España y Turquía atraían la atención general, porque ambas naciones tenían la llave del Mediterráneo. En cuanto a la posición de España, decía el ministro, se prestaba a

\footnotetext{
${ }^{8}$ Francisco Gómez Jordana: ministro de Asuntos Exteriores español desde el 4 de septiembre de 1942 hasta agosto de 1944.
} 
que se hiciese todo género de cábalas acerca del papel que le había de corresponder en los graves acontecimientos que se avecinaban, que pudieran ser, tal vez, decisivos para llegar a una paz concertada. La idea del diplomático español era la de poder mantener la posición de aquel momento, o sea, la neutralidad, única que convenía a España.

Se basaba para tener fe en que pudieran mantenerse así, por un lado, en la impresión que personalmente, y a través de sus embajadores en Londres y Washington, recogía la actitud de los anglosajones con respecto a España, que era francamente amistosa y con constante reiteración de las garantías que nos ofrecieron de no atacarnos y, de otro lado, la lógica, que le parecía no aconsejaba a esos países extender la guerra a España, cuya neutralidad les permitía en aquel momento tener libres sus comunicaciones a través del Estrecho y verse a salvo del inmenso peligro que constituiría para su navegación el que el Eje contase con las bases españolas.

En cuanto a Alemania, decía el ministro al embajador, conociendo como conocía ésta cuál era nuestra situación militar, implicar a España en la guerra, tan solo podría traerle complicaciones.

Por otro lado, seguía exponiendo el ministro, Franco, en el discurso que pronunció en Barcelona había dicho claramente que la posición de España era contraria a entrar en la contienda y que solo anhelaba la paz. ${ }^{9}$

Es decir, que España mantenía su postura de neutralidad, que fue confirmada cuando el encargado de negocios de España en Irlanda, tras entrevistarse con el jefe de gobierno irlandés y preguntarle éste sobre su posición en la contienda, el diplomático español respondió: "En ningún terreno se atreve ni realmente puede este gobierno adoptar actitud que sea susceptible de desagradar a los aliados, y su firmeza y libertad no van más allá de su neutralidad a toda costa». ${ }^{10}$

Al respecto, el corresponsal inglés del periódico londinense The Times en Washington recogía algunas de las palabras de la entrevista que el embajador español en EE.UU., Cárdenas, mantuvo con el presidente norteamericano Roosevelt:

9 Archivo Ministerio Asuntos Exteriores (=A.M.A.E.). Fondo Renovado, legajo 2221, expediente 13. Despacho dirigido por el ministro de Asuntos Exteriores español al embajador de España en Berlín, Madrid, 22 de abril de 1943.

${ }^{10}$ Ibídem: Despacho dirigido por el encargado de negocios de España en Irlanda al ministro de Asuntos Exteriores español, Dublín, 5 de mayo de 1943. 
«Cuando el embajador de España, Sr. Cárdenas, visitó la semana pasada al presidente Roosevelt, le manifestó que España seguiría inflexible en su determinación de mantener la neutralidad» ${ }^{11}$.

En definitiva, España defendería la neutralidad por encima de cualquier otra consideración, pero eso sí, solo frente a los aliados, mientras colaboraría abiertamente con las potencias del Eje.

\section{FRANCIA VIOLA LA NEUTRALIDAD DE ESPAÑA}

La violación de la neutralidad de España es un tema poco conocido, pero con este trabajo se pretende clarificar que, efectivamente, dicha neutralidad fue violada durante la Segunda Guerra Mundial.

Como ya se ha dicho, España declaraba la más estricta neutralidad a primeros de septiembre de 1939, pero, dos meses después, el ejecutivo español denunciaba al gobierno francés por violar el espacio aéreo español. No era la primera vez que Francia lo había hecho. Ya lo hizo en los meses previos al comienzo de la guerra. En aquella ocasión, el ministro de Asuntos Exteriores español, Coronel Beigbeder, comunicaba al gobierno galo que aviones postales franceses habían sobrevolado el archipiélago de las Baleares. Estas infracciones, según la reglamentación española, fueron cometidas el 17 de agosto de 1939 en Menorca, y el 30 y 31 del mismo mes en Ibiza.

Tras las quejas presentadas por la Embajada de España en París, el gobierno francés prometió interesarse por el tema. Hechas las pertinentes investigaciones, el ejecutivo galo comunicó al embajador español que la compañía Air France, responsable de los actos, en aquel momento no podía contestar a las preguntas, pues, la mayor parte de los pilotos estaban movilizados.

Únicamente, el piloto Leclaire, que había realizado el viaje Argel-Marsella pudo ser interrogado. Dicho piloto declaró que no había sobrevolado la isla de Menorca en el curso de aquel viaje, sin embargo, el ministro del Aire, general Yagüe, pudo comprobar que la compañía Air France, durante los meses de julio y agosto de 1939, no solo había efectuado el recorrido Argel-Marsella, sino que también había sobrevolado las Baleares, dado que esta vía era obligatoria para cubrir la línea Bélgica-Congo Belga.

En cualquier caso, lo cierto era que las infracciones habían sido efectuadas por los aparatos franceses. Por ello, y ante la insistencia del gobierno español, la

${ }^{11}$ Ibídem: De una emisión de Radio Londres, 11 de mayo de 1943. 
compañía Air-France llamaría de nuevo la atención a sus pilotos sobre la absoluta necesidad de respetar la reglamentación relativa al sobrevuelo de las islas Baleares, máxime, cuando la guerra ya había comenzado y España había declarado la estricta neutralidad $^{12}$.

No debió surtir efecto la llamada de atención de la compañía Air France a sus pilotos, cuando, poco después, el embajador de España en París comunicaba al ministro de Asuntos Exteriores español que, de nuevo, un avión correo francés había sobrevolado la zona prohibida de Ibiza el 21 de septiembre ${ }^{.13}$ Otra vez, la embajada española presentaba sus quejas al gobierno francés, y éste le respondía que ya se habían dado las instrucciones necesarias a los pilotos galos que hacían el servicio de la línea Marsella-Argel para evitar el sobrevuelo de las islas Baleares, particularmente en la zona de Ibiza.

De la investigación efectuada por las autoridades francesas se desprende que, según el piloto, éste pasó a 15 millas de la isla de Ibiza ${ }^{14}$. Es decir, que no sobrevoló dicha isla, cuando quedó demostrado que sí lo hizo.

A pesar de la insistencia del ejecutivo galo que sus aviones no habían volado sobre Ibiza, lo cierto es que Francia seguía violando el espacio aéreo español. Al menos, así lo comunicaba el gobernador civil de Gerona al ministro de Asuntos Exteriores español:

«Tengo el honor de participar a V.E. para los efectos que estime oportunos que por el Inspector-jefe de Investigación y vigilancia de Port-Bou en oficio fecha de ayer se me comunicaba que a las nueve horas de dicho día ha volado sobre mencionada población vuelo bajo un aparato de reconocimiento francés durante unos diez u once minutos, siendo este hecho la segunda vez que se realiza en breve espacio de tiempo» ${ }^{15}$

Pocos días después, el ministro del Aire, el general Yagüe, también hacía saber al ministro de Asuntos Exteriores que el día 10 de mayo de 1940 a las 9,45 horas, y a la altura de mil metros sobre el Coto de Doñana, junto a la desembocadura del río

12 A.M.A.E.: Fondo Renovado, legajo 1190, expedientes 3-21. Carta dirigida por el ministro de Asuntos Exteriores español a la Embajada de España en París, Madrid, 8 de noviembre de 1939.

13 Ibídem: Despacho dirigido por el embajador de España en París al ministro de Asuntos Exteriores español, París, 14 de noviembre de 1939.

14 Ibídem: Copia de la nota dirigida por el ministro de Negocios Extranjeros de Francia al embajador de España en París, París, 12 de noviembre de 1939.

15 Ibídem: Oficio dirigido por el ministro de la Gobernación al ministro de Asuntos Exteriores español, Madrid, 11 de mayo de 1940. 
Guadalquivir, un piloto que efectuaba vuelos de prácticas en aquella región vio un hidroavión que ostentaba los distintivos franceses. Dicho piloto se situó a la altura del hidroavión y le acompañó hasta llegar a seis o siete millas de la costa, pudiendo observar que se trataba de un hidroavión bimotor militar armado.

Otro ejemplo de violación, y en este caso reiterativo, era al que se refería la denuncia que hacía el jefe de las Fuerzas Aéreas de Baleares comunicando al ministro de Asuntos Exteriores español que un avión civil francés había volado sobre aquel territorio sin autorización, por lo que había cursado órdenes a todas las regiones aéreas para que, en caso de repetirse estos hechos, los aviones de caza españoles abriesen fuego sobre los aeroplanos extranjeros que volasen sin autorización el territorio nacional $\mathrm{y}$, en cualquier caso, sobre zonas prohibidas. ${ }^{16}$ Semejante petición hacía el subsecretario del Ministerio de Estado al embajador español en París ${ }^{17}$.

Pero, Francia seguía violando la neutralidad de España. El Estado Mayor de la Armada participaba al Ministerio de Asuntos Exteriores que el 12 de junio de 1940, al pasar frente a Tarifa un portaviones y dos destructores ingleses escoltados por un avión francés, éste voló sobre la isla de La Paloma ${ }^{18}$, y aunque le hicieron varios disparos, el avión galo se retiró sin novedad ${ }^{19}$.

Sin embargo, los aviones franceses no solo habían sobrevolado el espacio aéreo de las Baleares, sino que, ahora, aterrizaban en suelo español. Prueba de ello es el comunicado que el general Yagüe enviaba al ministro de Asuntos Exteriores diciéndole que según el jefe de las fuerzas Aéreas de Baleares, el 18 de junio de 1940 aterrizó en Palma de Mallorca a las 3 horas y 3 minutos un avión Potez, n n $^{\circ}$ 54 , y que ese mismo día había aterrizado otro avión a las 10 horas en las playas de Valencia a consecuencia de las averías producidas en el motor. Se trataba de un avión bimotor de reconocimiento francés, marca Lioret, matrícula LS. 405, que se dirigía desde Marsella a Orán. El aparato se incendió nada más aterrizar, aunque todos sus tripulantes resultaron ilesos.

${ }^{16}$ Ibídem: Despacho dirigido por el ministro del Aire al ministro de Asuntos Exteriores español, Madrid, 16 de mayo de 1940.

17 Ibídem: Minuta dirigida por el subsecretario de Estado al embajador de España en París, Madrid, 20 de mayo de 1940.

18 Isla de la Paloma: La isla de la Paloma se encuentra en Punta Carnero (Algeciras).

19 A.M.A.E.: Fondo Renovado, legajo 1190, expedientes 3-21. Minuta dirigida por el subsecretario de Estado al embajador de España en París, Madrid, 21 de junio de 1940. 
Por tanto, en virtud de las disposiciones en vigor sobre personal militar perteneciente a países beligerantes, el Ministerio del Aire había dado la orden a los jefes de las áreas $2^{\mathrm{a}}$ y $3^{\mathrm{a}}$ y zona aérea de Baleares, a las que pertenecían los puntos de aterrizaje, para el internamiento de aviones y tripulantes, quedando éstos en libertad con la obligación de presentarse diariamente a la autoridad militar local. En consecuencia, quedaban internados en Almería los tripulantes del primer avión citado (Coto de Doñana); en un pueblo del interior de Palma de Mallorca, aún no designado, los del segundo, y en Oliva (Valencia) los del tercero ${ }^{20}$.

Tras las conversaciones mantenidas entre el ministro de Asuntos Exteriores español y el conde de la Baume, embajador de Francia en España, el Ministerio de Asuntos Exteriores anunciaba que liberaría a los tripulantes internados en España tras el aterrizaje forzoso de sus aviones ${ }^{21}$.

Por su parte, el ministro de Marina decía que según el Ayudante de Marina del Puerto de la Selva ${ }^{22}$, a las 8 horas y 15 minutos del 21 de junio de 1940, volaron sobre territorio nacional cinco aviones franceses en dirección a Cabo Creus, pero que la artillería antiaérea abrió fuego contra ellos y, al momento, desaparecieron ${ }^{23}$.

Poco después, el cónsul de España en Gibraltar comunicaba al ministro de Asuntos Exteriores que el 30 de junio, aproximadamente a las 5 de la tarde, aparecieron sobre el campo de fortificaciones lindante con Gibraltar tres aeroplanos de nacionalidad francesa que, al parecer, intentaban aterrizar a poca distancia en el aeródromo británico que estaba en vías de construcción. Al persistir volar sobre la línea española, las ametralladoras instaladas en territorio español abrieron fuego contra ellos, derribando un avión que cayó al mar envuelto en llamas en aguas de este puerto. Según se dijo, resultó también tocado otro de los aviones mencionados.

De los tripulantes del aeroplano derribado, dos, al menos, murieron. El entierro se celebraría por la tarde, pero los ánimos de los extremistas y algunos españoles refugiados se hallaban bastante excitados contra España y sus autoridades militares y, según el cónsul, no sería de extrañar que se produjera alguna manifestación o

${ }^{20}$ Ibidem: Despacho dirigido por el ministro del Aire al ministro de Asuntos Exteriores español, Madrid, 20 de junio de 1940.

${ }^{21}$ Ibidem: Nota verbal dirigida por el embajador de Francia en Madrid al ministro de Asuntos Exteriores español, Madrid, 27 de junio de 1940.

22 Puerto de la Selva: Port de la Selva, municipio español perteneciente a la comarca del Alto Ampurdán en la provincia de Gerona, Cataluña, ubicado en la costa norte del cabo Creus, en la costa Brava.

${ }^{23}$ A.M.A.E.: Fondo Renovado, legajo 1190, expedientes 3-21. Minuta dirigida por el ministro de Marina al ministro de Asuntos Exteriores español, Madrid, 22 de junio de 1940. 
desorden con motivo de la ceremonia fúnebre. En cambio, la prensa local se mostraba respetuosa con España. Al parecer, hasta aquel momento, eran doce los aviones franceses que habían logrado salir de Francia o del Marruecos francés y aterrizar en Gibraltar ${ }^{24}$.

Como era de esperar, la embajada de Francia en España se dirigió al Ministerio del Aire para pedir la intervención del mismo en apoyo de su demanda, para que fuesen puestos en libertad y pasasen a Francia por la frontera de Port Bou a partir de 2 de julio de 1940, los pilotos franceses que habían aterrizado en territorio español y habían sido internados en distintas partes de España. A saber ${ }^{25}$ :

En Valencia ocho oficiales y nueve suboficiales; en Mataró dos suboficiales; en Málaga dos suboficiales; en la Línea de la Concepción un oficial y dos suboficiales, y en las islas Baleares cuatro oficiales y seis suboficiales.

También pedían que se pusieran en libertad los tripulantes polacos internados en España, permitiéndoles el paso desde ésta a Francia por la frontera de Port Bou a partir del 2 de julio de 1940. En este caso habían sido internados en Valencia cuatro oficiales y seis suboficiales ${ }^{26}$.

A juicio del Ministerio del Aire, y según el armisticio establecido con Francia, podían ser puestos en libertad los pilotos, pero tenían que ser retenidos los aparatos hasta que posteriormente se resolviera sobre ellos, habida cuenta de que el armisticio no tenía más alcance que el de un acuerdo para la interrupción temporal de las hostilidades. El armisticio no podía ser lo mismo que el tratado de paz que se firmaba al terminar la guerra, con todas las consecuencias jurídicas que ello implicaba; por tanto, el estado de guerra subsistía, no solo entre los beligerantes, sino también entre beligerantes y neutrales.

Así, el derecho de visita y registro de los barcos neutrales por los barcos de guerra beligerantes permanecía intacto a pesar de la conclusión del armisticio, por lo que era posible la captura de las embarcaciones que transportaban contrabando de guerra. Si esta facultad de los beligerantes no era alterada por la conclusión del armisticio, ni que decir tiene que tampoco se modificaba ninguno de los derechos y deberes que contenía el status de la neutralidad.

24 Ibídem: Despacho dirigido por el cónsul de España en Gibraltar al ministro de Asuntos Exteriores español, Gibraltar, 1 de julio de 1940.

${ }^{25}$ Ibídem: 1 de julio de 1940.

${ }^{26}$ Ibídem: 1 de julio de 1940. 
Entre los deberes destacaba el de internar a las fuerzas armadas beligerantes que buscasen refugio en territorio neutral, ya que su puesta en libertad les permitiría regresar a su país e incorporarse de nuevo al ejército del que formaban parte. Y es justamente esta posibilidad la que debían impedir los neutrales en cuyo territorio se refugiaban fuerzas armadas beligerantes, pues, les obligaba a ello su condición de neutrales, condición que subsistía durante la vigencia del armisticio ${ }^{27}$.

Es decir, que los tripulantes tenían que ser internados. Sin embargo, esto contrasta con la actitud de Franco hacia los militares alemanes e italianos que aterrizaban en suelo español y eran puestos en libertad inmediatamente como se verá después.

\section{ALEMANIA E INGLATERRA VIOLAN LA NEUTRALIDAD DE ESPAÑ̃}

\subsection{El caso de Alemania}

Como es harto sabido, Alemania violaba la estricta neutralidad que España declaraba al principio de la guerra. Así se desprende de un documento del ministro de Asuntos Exteriores español en el que hacía saber a la embajada de Alemania en Madrid que el 24 de junio de 1940 entró en el puerto de Pasajes el bou español Santa Clara, y que encontrándose a unas 70 millas al norte de San Sebastián (meridiano de San Sebastián y paralelo de Arcachon), o sea, a 32 millas de la costa francesa, fue agredido por 12 trimotores alemanes que empezaron a tirar bombas sobre él.

La tripulación abandonó el buque en botes, a excepción de cuatro hombres que quedaron a bordo y de los cuales uno se arrojó al mar sin que se hubiese vuelto a tener noticias suyas. Los aparatos continuaron lanzando bombas y ametrallando el Santa Clara, ocasionándole diversas averías de pequeña importancia y muchos impactos de ametralladora. Por otro lado, en las proximidades donde había ocurrido dicho incidente se encontraba recogiendo su carga el pesquero español Gure Ytxaropena, que, si bien no fue agredido, perdió sus aparejos al abandonar a toda prisa aquellos lugares.

El Ministerio de Asuntos Exteriores español no dudaba que la agresión alemana obedecía exclusivamente a una equivocación -a decir verdad quería justificar dicha agresión- y que, por ello mismo, no había lugar a temer que se repitiera, pero confiaba también que el gobierno del Reich, en atención a que se trataba de gente humilde, estuviese dispuesto a indemnizar a los propietarios de los mencionados

27 Ibídem: Informe remitido por la Asesoría Jurídica Internacional al ministro de Asuntos Exteriores español, Madrid, 5 de julio de 1940. 
pesqueros por los daños sufridos, así como a indemnizar a la familia del tripulante que se arrojó al agua, siempre que se confirmase su fallecimiento ${ }^{28}$.

Pocos días después, el ministro de Marina comunicaba al ministro de Asuntos Exteriores que, en relación con los armadores de los pesqueros españoles Santa Clara y Gure Ytxaropena, bombardeados por aviones alemanes el 24 de junio pasado, las autoridades alemanas tasaban los daños y pérdidas respectivamente habidas en cada uno de ellos en 20.000 pesetas $^{29}$. En esta ocasión, el gesto positivo del ejecutivo alemán no podía por menos que halagar al gobierno español, el que, por su parte, calificó el incidente de equivocación.

\subsection{El caso de Inglaterra}

Inglaterra, aunque no cesó de denunciar a Alemania ante España por violar la neutralidad española durante la guerra, ella también hacía lo propio. El Ministerio de Asuntos Exteriores español saludaba atentamente al Embajador de Gran Bretaña en Madrid y le exponía que dos aviones españoles del tipo Saboya 17 volaban juntos desde las islas Baleares hacia el mar, y cuando se encontraban lejos de una Escuadra inglesa, ésta abrió el fuego de cañón sobre los mencionados aviones que dieron la vuelta inmediatamente con dirección a sus barcos.

Muy cerca ya de tierra, uno de esos aviones lanzó la llamada de S.O.S. Inmediatamente salieron dos barcos y algunos hidroaviones que reconocieron el lugar desde donde el avión había pedido auxilio, encontrando en el mar un ala y varios depósitos del aparato completamente destrozados a balazos.

Según el general Kindelán ${ }^{30}$, el aeroplano fue atacado por cazas ingleses que hicieron sobre él diversas pasadas, pues eran varias las direcciones en las que aparecían los impactos sufridos ${ }^{31}$.

El mismo día, el Ministerio de Asuntos Exteriores enviaba a la embajada inglesa una nota rogándole que recabase de su gobierno todo tipo de datos y se

28 Ibídem: Informe dirigido por el ministro de Asuntos Exteriores español a la Embajada de Alemania en Madrid, Madrid, 5 de julio de 1940.

${ }^{29}$ Ibídem: Despacho dirigido por el ministro de Marina al ministro de Asuntos Exteriores español, Madrid, 7 de octubre de 1940.

${ }^{30}$ General Kindelán: Alfredo Kindelán, militar y aviador español. Fue el fundador del ejército del Aire actual.

31 A.M.A.E.: Fondo Renovado, legajo 1190, expedientes 3-21. Nota verbal dirigida por el subsecretario del Ministerio del Ejército al subsecretario del Ministerio de Asuntos Exteriores, Madrid, 12 de noviembre de 1940. 
abriese con la máxima urgencia una investigación sobre los hechos ocurridos, cuya trascendencia no era necesario subrayar, y esperaba ser informado tanto de las medidas que se tomasen en este asunto, como de las disposiciones que se acordasen para evitar su repetición.

En cualquier caso, el incidente, aunque pequeño, era una agresión en territorio español con todas las de la ley. Es decir, que no solo los aliados, sino también las potencias del Eje, violaron la neutralidad española durante la guerra.

\section{PROTESTA DE LA EMBAJADA DE GRAN BRETAÑA EN ESPAÑA POR LAS FACILIDADES DADAS POR ÉSTA A LAS POTENCIAS DEL EJE EN TERRITORIO ESPAÑOL}

$\mathrm{Si}$ antes era España la que denunciaba a Francia, Alemania e Inglaterra por violar la neutralidad española como se ha visto, ahora sería Inglaterra la que protestase ante España por el trato favorable dado por ésta a Alemania e Italia.

La Embajada de Gran Bretaña en Madrid manifestaba al ministro de Asuntos Exteriores español su queja referente a las facilidades, contrarias a la neutralidad, dadas por su gobierno a submarinos y buques de abastecimiento de las potencias del Eje en territorio español ${ }^{32}$, y aunque desde el Ministerio de Asuntos Exteriores se le había respondido que todas las quejas habían sido atendidas, la Embajada inglesa contestaba que el asunto hubiese quedado resuelto si todos los submarinos alemanes que navegaban por aguas españolas hubieran sido internados con sus tripulaciones, como estaba ocurriendo con los franceses, en vez de haberles permitido que se marcharan.

$\mathrm{Y}$ respecto a los buques de abastecimiento (siete en total, incluyendo dos buques cisterna en Vigo), seguía diciendo la Embajada inglesa, deberían haber sido internados cuando se llamó la atención sobre ellos por primera vez, en lugar de dejarlos disponibles para los submarinos durante dos o tres años en los puertos claves españoles de Vigo, Cádiz y Las Palmas. En fin, continuamente, y a pesar de las quejas, España hacía oídos sordos a las denuncias de la Embajada británica.

Por esta razón, el ministro de Asuntos Exteriores inglés envió una carta a Serrano Súñer $^{33}$ el 27 de julio de 1942, diciéndole que para evitar nuevos peligros

32 Morcillo, M. (2000). «España y las potencias del Eje a través de la correspondencia diplomática española, 1937-1945», Ensayos, 15. Albacete: Escuela Universitaria de Magisterio, p. 102.

${ }^{33}$ Serrano Súñer: Ramón Serrano Súñer, cuñado de Franco. Fue ministro de Asuntos Exteriores desde el 17 de octubre de 1940 hasta el 3 de septiembre de 1942. 
de comprometer la neutralidad de España por incidentes con submarinos alemanes, sería beneficioso para los intereses del gobierno español proceder como fue impelido a hacerlo en 1917 después de una serie de incidentes embarazosos durante la gran guerra europea, y prohibir a todos los submarinos beligerantes y sus tripulantes entrar en puertos españoles bajo pena de ser internados.

Es decir, que el Ministerio de Asuntos Exteriores inglés, para evitar un posible enfrentamiento entre los gobiernos español y británico, instaba a España a que siguiera la conducta mantenida durante la Primera Guerra Mundial. España estudiaría con detenimiento esta proposición, pero, de momento, hacía caso omiso.

Si esto sucedía con los buques y submarinos, otro tanto ocurría con los aviones y sus tripulaciones en aterrizaje forzoso. Así, durante más de dos meses y medio fueron repatriadas inmediatamente las tripulaciones de aviones de las potencias del Eje en aterrizaje forzoso, mientras que los tripulantes de aviones británicos fueron internados.

Pero no solo era esto, sino que la Embajada británica denunciaba también que el gobierno español les había permitido a los agentes del Eje la organización de un servicio muy grande, principalmente en Sevilla, Huelva, La Línea, Algeciras y Melilla, dedicado al sabotaje de buques británicos y, a pesar de las continuas protestas del gobierno inglés, hasta el momento, aquella organización estaba más activa que nunca.

Además, los alemanes habían construido en territorio español a los dos lados del Estrecho una vasta organización de espionaje que trabajaba contra Estados Unidos, y habían instalado con inmunidad emisoras de radio en la Villa de León, en Algeciras, con aparatos de observación en otra villa vecina, y otras emisoras y puestos de observación en Ceuta y en Tánger. Los italianos, además de tener una misión militar en Ceuta (cosa difícil en sí de explicar) mantenían una emisora de radio en la misma población.

Durante tres años y medio el paso por territorio nacional o el viaje en barcos españoles había sido prohibido a las personas civiles de nacionalidad británica en edad militar. En cambio, los alemanes e italianos, también en edad militar, habían podido pasar por territorio español a su gusto.

Pero esta actitud benevolente hacia las potencias del Eje cambiaría. Franco, al tener noticia de que se estaba preparando el desembarco aliado en el norte de África, y que España y sus territorios no correrían peligro, modificó su postura. El 3 de junio de 1942 el Ministerio de Asuntos Exteriores enviaba a la Embajada de Gran Bretaña una Nota, cuyo último párrafo decía: 
«... Puede el gobierno de Su Majestad Británica tener la seguridad más absoluta de que el territorio de la España no beligerante no será utilizado por ningún beligerante, y asi mismo que los buques de la Gran Bretaña y sus aliados nunca podrán ser atacados por los buques y aviones alemanes o italianos como consecuencia de los avisos de las instalaciones de referencia que el gobierno español montaba en función de soberanía para atender a las necesidades de su defensa...»

Sin embargo, y a pesar de esta promesa, desde aquella fecha la Embajada británica había dirigido unas 15 notas al Ministerio de Asuntos Exteriores español quejándose por los actos ilícitos del $\mathrm{Eje}^{34}$. Al final, y según el gobierno inglés, de nada habían servido las protestas que había hecho durante 19 meses, pues, Alemania principalmente, seguía cometiendo actividades prohibidas ${ }^{35}$.

Ahora bien, no era de extrañar la actitud de España, si tenemos en cuenta que, a pesar de la declaración de estricta neutralidad, Franco mantuvo relaciones amistosas y, por qué no decirlas, de colaboración, con las potencias del Eje entre 1939 y 1944.

\subsection{Actitud favorable de Inglaterra hacia España al finalizar la guerra}

Al final del conflicto, la opinión de la Embajada británica hacia España durante la contienda, contraria a la actitud de Franco respecto a las potencias del Eje, contrastaría con las declaraciones favorables de Winston Churchill sobre la posición de España en la Segunda Guerra Mundial, aunque, también es cierto que Churchill, cuando Franco pasó de la no beligerancia a la estricta neutralidad, como gesto positivo, en mayo de 1944, pronunció un discurso favorable a España en la Cámara de los Comunes ${ }^{36}$.

Una vez terminada la guerra, Churchill publicaba un artículo en más de 24 periódicos de Inglaterra muy favorable para España, bajo el título: Cuál fue la actitud española. En dicho artículo Churchill señalaba entre otras cosas:

«En aquella época los alemanes habían indicado al gobierno español que posiblemente llevarian a cabo una marcha triunfal a través de España, que

\footnotetext{
34 Morcillo, M. (2000). «España en la política internacional a través de la correspondencia diplomática 1940-1948» En El franquismo, el régimen y la oposición. Vol. I. Guadalajara: Ministerio de Educación, Cultura y Deporte y Junta de Comunidades de Castilla-La Mancha, p. 246.

35 A.M.A.E.: Fondo Renovado, legajo 5162, expediente 1: Memoria dirigida por el embajador de Gran Bretaña en Madrid al ministro de Asuntos Exteriores, Madrid, 24 de diciembre de 1943.

36 Pereira, J.C. y P. Martínez Lillo. (1998). «Política exterior, 1939-1975». En PARedes, J. (Coord.). Historia Contemporánea de España (siglo XX) ..., pp. 735.
} 
permitiría a ésta apoderarse de Gibraltar. La empresa parecía fácil en el terreno teórico, pero llevarla a la práctica implicaba, sin duda, grandes dificultades. Sin embargo, era también probable que si España hubiese cedido a los halagos y a las presiones de los alemanes, el peso que hubiera caído sobre Inglaterra habría sido considerable».

El Estrecho de Gibraltar habría sido clausurado automáticamente y hubieran quedado cerrados todos los accesos al Mediterráneo, convirtiéndose las costas españolas en refugios ideales para los submarinos alemanes...

...nadie merece más alabanzas que la propia España por haberse mantenido al margen de la guerra. Los españoles estaban hartos de combatir y no querían empezar de nuevo...

Hacía ya tiempo que habíamos ampliado nuestro aeropuerto de Gibraltar, prolongándolo hacia el mar, y durante más de un mes, antes de la hora cero del 7 de noviembre de 1942, habiamos visto seiscientos aparatos al descubierto en el citado aeródromo y al alcance de las baterías españolas. Era dificil hacer creer a los españoles que aquellos aviones estaban destinados a reforzar Malta; por ello, nuestras ansias estaban sobradamente justificadas.

No obstante, los españoles conservaron su actitud amistosa y se mantuvieron reservados y tranquilos. No nos hicieron ninguna pregunta y no dieron lugar a ningún incidente. A pesar que en algunas ocasiones hicieron «la vista gorda» respecto a algún submarino alemán y continuaron exportando productos a Alemania, por obtener de estas exportaciones importantes ventajas financieras, no cabe duda que la actitud española nos favoreció grandemente.

Alemania ignoraba la existencia de la masa de nuestros aviones situados en Gibraltar y la presencia en este puerto de un enorme número de buques que, a veces, y bajo el control de las baterías de costa española, se extendian fuera de la zona de Gibraltar hasta adentrarse en la bahía de Algeciras...

...Es por este motivo por el que nunca podré olvidar el servicio prestado por España, no sólo al Reino Unido, al Imperio británico y a la Commonwealth, sino también a la causa de las Naciones Unidas...

...Esto explica mi posición amistosa respecto a España, una vez pasada la tempestad, porque, además, tengo la esperanza de que España pueda ejercer en el Mediterráneo un fuerte influjo pacificador...» ${ }^{37}$

A la vista de estas palabras, qué duda cabe que el papel desempeñado por España en la Segunda Guerra Mundial había sido decisivo para el triunfo final. Churchill nunca podría olvidar el servicio prestado por España.

${ }^{37}$ A.M.A.E.: Fondo Renovado, legajo 5162, expediente 5: Despacho dirigido por el embajador de España en Roma al ministro de Asuntos Exteriores, Roma, 29 de abril de 1947. 


\section{CONCLUSIONES}

La violación de la neutralidad de España durante la Segunda Guerra Mundial, a todas luces, resulta más que evidente como lo demuestran las reiteradas violaciones, no solo del espacio aéreo español sino también de territorio, por parte de los países aliados y las potencias del Eje.

Francia, entre septiembre de 1939 y junio de 1940, violó la neutralidad de España más de diez veces en diferentes puntos como Baleares, Valencia, Andalucía, etc., a pesar de las protestas y denuncias del ministro de Asuntos Exteriores.

En junio de 1940 Alemania también violaba la neutralidad de España bajo la atenta mirada del gobierno español, que intentaba justificarlo como un error. Por otra parte, en noviembre de 1940, Inglaterra violaba el espacio aéreo español, mientras el embajador británico en Madrid protestaba por las facilidades que Franco estaba dando a las potencias del Eje en territorio nacional. Hasta siete buques alemanes de abastecimiento que deberían haber sido internados, quedaron disponibles durante dos o tres años en los puertos claves de España como Vigo, Cádiz y las Palmas. Otro tanto ocurría con los submarinos y los aviones y sus tripulantes en aterrizaje forzoso, mientras los aparatos y la tripulación de los países aliados eran internados inmediatamente.

La mayor parte de las agresiones de violación por parte de los aliados se cometieron al principio de la guerra, durante la etapa de estricta neutralidad, frente a las potencias de Eje que, si bien, empezaron durante el periodo de no beligerancia, se mantuvieron prácticamente hasta casi el final de la contienda mundial, aun cuando Franco, a partir de 1943, había vuelto de nuevo a la neutralidad.

En definitiva, la estricta neutralidad defendida a ultranza por España durante la Segunda Guerra Mundial, solo fue aplicada a las potencias aliadas, en particular a Francia, a la que no cesará de denunciar durante la guerra por violar el territorio español, mientras colaboraba abiertamente con Alemania e Italia, pese a las protestas de Gran Bretaña, al menos, durante una gran parte del conflicto.

\section{BIBLIOGRAFÍA}

Buchanan, A. N. ( 2009). "Washington's 'silent ally' in World War II? United States policy towards Spain, 1939-1945» Journal of Transatlantic Studies 7, 2: 93-117.

EIROA, M. (2001). Las relaciones de Franco con Europa Centro-Oriental (1939-1955). Barcelona: Ariel.

FERNÁNDEZ HitA, A. (2006). «De la estricta neutralidad a la no beligerancia. La 
Vanguardia Española y la Solidaridad Nacional durante la Segunda Guerra Mundial» [recurso electrónico]. http://www.solidaritat.ub.edu/premi pau/2006/treballs/Estricta neutralidad.pdf [Consultado: 5 de junio de 2012].

FEST, J. (2005). Hitler, una biografía. Barcelona: Planeta

Churchill, W. S. (2004). La Segunda Guerra Mundial. Barcelona: Planeta.

Hillgruber, A. (1995). La Segunda Guerra Mundial. Objetivos de guerra y estrategia de las grandes potencias. Madrid: Alianza.

KERSHAW, I. (2000). Hitler. Madrid: Península.

MARTín ARTAJO, A. (1950). La política de aislamiento de España seguida por las naciones aliadas durante el quinquenio 1945-1950. Discurso pronunciado en la sesión plenaria de las Cortes españolas el 14 de diciembre de 1950, Madrid: OID.

Morales LezCANO, V. (1995). Historia de la no beligerancia española durante la Segunda Guerra Mundial. Gran Canaria: Ediciones del Cabildo Insular de Gran Canaria, $2^{\mathrm{a}}$. edición.

MorCiLlo, M. (2000). «España y las potencias del Eje a través de la correspondencia diplomática española, 1937-1945», Ensayos, 15, p. 102.

Morcillo, M. (2000) «España en la política internacional a través de la correspondencia diplomática (1940-1948)» En El franquismo, el régimen y la oposición, vol. I. Guadalajara: Ministerio de Educación, Cultura y Deporte y Junta de Comunidades de Castilla-La Mancha, pp. 239-250.

OchoA Brun, M.A. (1996). Historia de la diplomacia española. Madrid: Ministerio de Asuntos Exteriores.

Payne, S.G. y D. Contreras. (1996). España y la II Guerra Mundial. Madrid: Universidad Complutense.

PereirA, J.C. y P. MARTínez LiLlo. (1998). «Política exterior, 1939-1975». En PARedes, J. (Coord.). Historia Contemporánea de España (siglo XX). Barcelona: Ariel, pp. 729730 .

PReston, P. (1996). «Franco y la elaboración de una política personalista (1936-1953)», Historia Contemporánea. Nombres propios para una diplomacia, Hispania Nova, 15.

Stanley, G. P. (2008). Franco and Hitler. New Haven: Yale University Press.

Stanley, G. P. (2008). Franco and Hitler : Spain, Germany, and World War II. Yale University Press, New Haven (Connecticut).

Stanton, S. (2009). «The Myth of Spain Neutrality: U.S. Foreign Relations with Spain, 1939-1941». [recurso electrónico]. http://artsci.drake.edu/dussj/stantonsean.pdf. [consultado: 13-7-2012].

Tusell, J. (1995). Franco, España y la II Guerra Mundial. Entre el Eje y la neutralidad. Madrid: Temas de Hoy. 
Matilde Morcillo

\section{ANEXOS}

\section{Relación de tripulantes franceses internados en España}

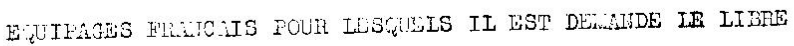

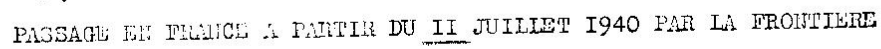

DE PORT BOU

$= \pm==== \pm==$

6

Equipaces inlenús in VILiCE :

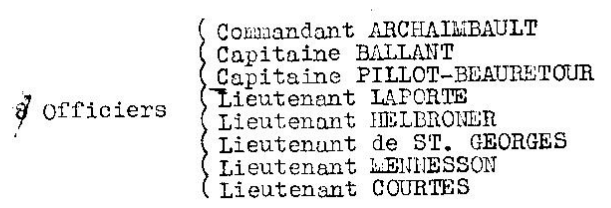

(Adjudant-Chef IECOMTE

Adjudunt-Chef CAPDEVIELLE

5 S/Officiers $\left\{\begin{array}{l}\text { Adjudant NOAN } \\ \text { Adjuant BOURDIN }\end{array}\right.$

Adjudant SAIDLPLiNS

Sercent-Chef BOUILIES

Sergent conjLLOHI

Caporal $\mathrm{TE}$ Y YNES

Liécanicien HOCHET

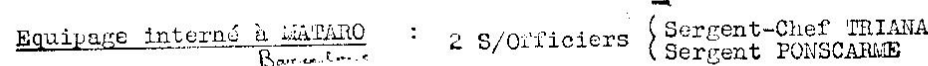

Equipage interné ì Hifiga : 2 S/Orficiers (Sergent PESCAT

(Lúcanicien BONIFAY

Equipage interné à LA LIIJEA : 1 officier (Lieutenant CAIJAL d'ENGASSAC

$\frac{\text { de la Conception }}{6 . \cdots+}=2$ s/officiers (RISSO

Equipages interné aux Iles : BATEARES

4 officiers $\left\{\begin{array}{l}\text { Lieutenant GAIIISL } \\ \text { Lieutenant CIAVET } \\ \text { S/Iieutenant DOLEAC } \\ \text { S/Lieutenant LEGOIGNEC }\end{array}\right.$

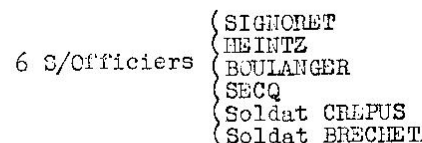

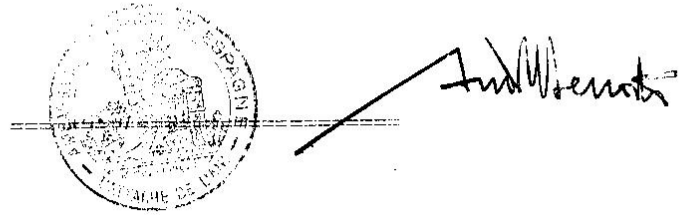

Fuente: A.M.A.E., Legajo 1190 
Violación de la neutralidad de España durante la Segunda Guerra Mundial

\section{Relación de tripulantes polacos internados en España}

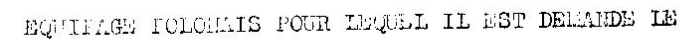

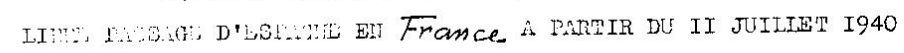

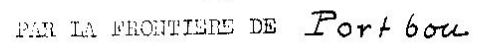

$==:==-:= \pm== \pm==$
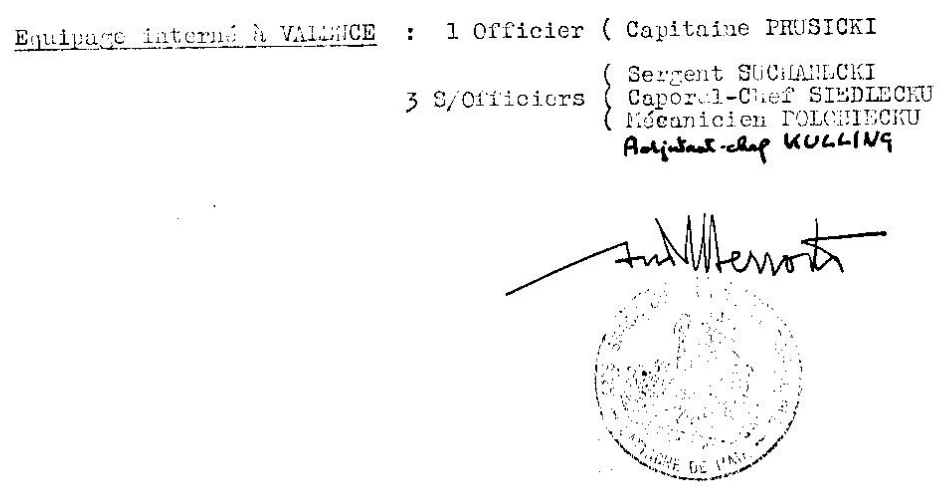

Fuente: A.M.A.E., Legajo 1190 